\title{
Evaluation of Effect of Low-Density Lipoprotein Levels on the Measurement of Hepatitis C Viral Load in Chronic Hepatitis C Patients
}

\author{
Basma B. Hasan', Essam M. Abdalla', Abdul Malek M. Nasar', Nahed Youssef ${ }^{1 *}$, \\ Ahmed A. El Hawary ${ }^{2}$
}

Departments of ${ }^{1}$ Clinical Pathology and ${ }^{2}$ Internal Medicine, Faculty of Medicine, Suez Canal University, Egypt

\begin{abstract}
Background: Low density lipoprotein receptor (LDLR) has been proposed as a candidate receptor for hepatitis $\mathrm{C}$ virus (HCV). Free beta-lipoproteins in a human serum may regulate the rate of hepatocyte infection by competing with the virus. Therefore, serum HCV levels should be regulated by rise and fall of serum beta-lipoproteins since the infection rate of virions influences HCV replication in hepatocytes and release of virions by hepatocytes. Aim: To evaluate effect of lowdensity lipoprotein levels on the measurement of hepatitis $C$ viral load in chronic hepatitis $\mathrm{C}$ patients and estimate the levels of viral load of hepatitis $C$ in relation to variation of the corresponding low-density lipoprotein levels in chronic hepatitis $\mathrm{C}$ patients and their relations to each other. Subjects and Methods: $30 \mathrm{HCV}$ hyperlipidemic patients were subjected to clinical evaluation and laboratory investigations included follow up by repeated measurements of LDL level, AST, ALT, and Albumin for patient selection. Results: There was an inverse statistically significant correlation ( $r=-0.388, p=0.034$ ) between the HCV RNA absolute viral load differences and LDL level absolute differences (the lower the LDL differences, the higher the HCV RNA differences). Also, there was an inverse statistically significant correlation $(r=-0.42, p=0.021)$ between HCV RNA absolute differences and LDL level percent differences (the higher the LDL percent differences, the lower the HCV RNA absolute differences).The predictive variables for HCV RNA viral load level differences were LDL level differences and LDL percent differences whereas AST, ALT, and Albumin differences were not. Conclusion: Low-density lipoprotein levels have an effect on the measurement of hepatitis $\mathrm{C}$ viral load in chronic hepatitis $\mathrm{C}$ patients. Therefore, this must be taken in consideration when chronic hepatitis $\mathrm{C}$ patients have a history of dyslipidemia and perform a HCV RNA viral load by PCR.
\end{abstract}

Key words: HCV, LDLR, LDL-cholesterol

\section{Introduction}

Hepatitis C virus (HCV) infection is a major cause of chronic liver disease worldwide. HCV infection is a very important health problem in Egypt, with seroprevalence rates of $10-20 \%$ among volunteer blood donors, and even higher rates reported among segments of the general population $^{(1)}$. Low-density lipoprotein (LDL) refers to a class and range of lipoprotein particles, commonly referred as "bad cholesterol" due to the link between high LDL levels and cardiovascular diseases leading to myocardial infarctions and strokes ${ }^{(2)}$. Low-density 
lipoprotein receptors (LDLR) are plasma membrane proteins, which are widely expressed, and are capable of binding with high affinity to circulating LDL particles through their interaction with apolipoprotein $\mathrm{B}-100^{(3,4)}$. Hepatitis $\mathrm{C}$ virus $(\mathrm{HCV})$ is known to cause acute and/or chronic hepatitis. HCV not only infects hepatocytes but also different cell types and replicates in those cells ${ }^{(5-11)}$. Therefore, investigators are interested in identifying the $\mathrm{HCV}$ receptor(s). Recent investigations showed that particles of HCV exist in binding form with beta-lipoproteins (low density lipoprotein [LDL] and very low density lipoprotein [VLDL]) and immunoglobulins ${ }^{(12-14)}$. In addition, some groups reported that the LDL receptor (LDLR) is one of the $\mathrm{HCV}$ receptors ${ }^{(15,16)}$. Experi-ments in vitro showed competitive inhibition of binding between HCV and LDLR by purified LDL ${ }^{(16)}$. If similar inhibition occurs in vivo, the serum concentration of beta-lipo-proteins should influence HCV concentration, since cell infection is required for replication and proliferation of viruses. To examine this possibility we collected data on serum concentrations of LDL and HCV RNA viral load in patients with chronic type $C$ hepatitis, and statistically analyzed the relationship betw-een HCV RNA viral load and LDL level.

\section{Subjects and Methods}

The study was carried out in the internal medicine clinic in Suez Canal University Hospital in Ismailia. The present work studied 30 adult patients; attended the clinic for follow up of their hyperlipidemia ; all patients were chronic hepatitis $C$ patients attended the clinic more than one time with LDL levels difference of no less than $10 \%$ at two successive visit were followed up. Patients receiving anti-viral treatment for $\mathrm{HCV}$, receiving treatment for hyper- lipidemia, or suffering from chronic liver disease due to causes other than HCV were excluded. All participants were subjected to medical history taking, complete clinical examination and base-line laboratory investigations: $L D L$ level, liver function tests (AST, ALT, and Albumin), and HCV RNA viral load.

Quantitative determination of LDL cholesterol

Direct determination of serum LDLc levels without the need of any pre-treatment or centrifugation steps. HDL, VLDL, and chylomicrons are specially hydrolyzed by detergent 1 . The released cholesterol contained in these lipoproteins reacts immediately in the enzymatic action of cholesterol esterase (CE) and cholesterol oxidase (CHOD) generating hydrogen peroxide. The latter is consumed by a peroxidase (POD) in the presence of 4-aminoantipyrine to generate a colorless product. During this first step, LDL particles remain intact. The reaction of LDL cholesterol is initiated by the addition of another detergent 2 together with a coupler, N, N-bis (4sulfobutyl)-m-toulidine (DSBmT). The second detergent releases cholesterol in the LDL particles, which are subjected to the enzymatic reaction in the presence of coupler to produce a colored product.

Quantitative determination of HCV-RNA level using (RT-PCR) assay

MagNA Pure Light Cycler total nucleic acid isolation kit was used for viral RNA extraction with the MagNA Pure. The Light Cycler version 3.5 instrument* was used for HCV RNA Amplification, detection and quantification using the TaqMan probe technology.

\section{Statistical analysis}

Collected data was entered into computer using SPSS program. Statistical analysis 
was done by SPSS statistical package. Full description and frequencies of data were tabulated and figured accordingly. For dichotomous variables, ANOVA and regression analysis tests were used, and chisquare was used for categorical variables. Regression analysis was done in order to find the predictors (independent variables) that affect dependent variable (HCV-RNA viral load) and find out an equation that can be used to calculate the level of the dependent variable.

\section{Results}

The age of the study population ranged from 20 to 58 years with a mean of $42.3 \pm 9.4$ years old. Males constituted 70\% (21/30) while females were $30 \%$ (9/30). In the present study, patients fulfilled the criteria of selection were followed up by performing LDL, AST, ALT, and Albumin until our target results for each patient were reached. The first (basal or high LDL group) results of LDL, AST, ALT and Albumin were designated as LDL1, AST1, ALT1 and Alb1 while the second (target or low LDL group) results of LDL, AST, ALT and Albumin were designated as LDL2, AST2, ALT2 and Alb2. In addition, for the same patients at different occasions of different LDL levels HCV RNA viral load results take the same prefix RNA1 and RNA2. The mean level of LDL in high LDL group was $137.8 \pm 12.4 \mathrm{mg} / \mathrm{dL}$ versus $94.85 \pm 14.7 \mathrm{mg} / \mathrm{dL}$ in low LDL group. The mean level of HCV-RNA in high LDL group was $3.12 \pm 2.14$ million $\mathrm{IU} / \mathrm{mL}$ versus $3.88 \pm 2.5$ million IU/ $\mathrm{mL}$ in low LDL group (Table 1). The mean liver profile levels of high LDL group was $36.7 \pm 15.8 \mathrm{U} / \mathrm{L}$ for $\mathrm{ALT}, 30.9 \pm 12.0$ $\mathrm{U} / \mathrm{L}$ for AST and $4.1 \pm 0.3 \mathrm{~g} / \mathrm{dL}$ for Alb versus 42.9 $\pm 17.2 \mathrm{U} / \mathrm{L}$ for $\mathrm{ALT}, 29.6 \pm 10.5 \mathrm{U} / \mathrm{L}$ for AST and $4.0 \pm 0.3 \mathrm{~g} / \mathrm{dL}$ for Alb in low LDL group(Table 1). By performing, a paired Ttest statistics between the first and second results of LDL, AST, ALT, Alb and RNA, there was a statistical significant difference between the first and second results in LDL $(p=0.00), \operatorname{HCVRNA}(p=0.00), \operatorname{ALT}(p=0.00)$ and Alb $(p=0.00)$.

Table 1: Liver profile and HCV-RNA levels in high LDL group versus low LDL group

\begin{tabular}{|c|ccc|}
\hline & $\begin{array}{c}\text { High LDL group } \\
(\mathrm{n}=30)\end{array}$ & $\begin{array}{c}\text { Low LDL group } \\
(\mathrm{n}=30)\end{array}$ & P value \\
\hline LDL $(\mathrm{mg} / \mathrm{dl})$ & $137.8 \pm 12.4$ & $94.85 \pm 14.7$ & $0.00^{*}$ \\
ALT $(\mathrm{U} / \mathrm{L})$ & $36.7 \pm 15.8$ & $42.9 \pm 17.2$ & $0.00^{*}$ \\
AST (U/L) & $30.9 \pm 12.0$ & $29.6 \pm 10.5$ & 0.05 \\
ALB (g/dL) & $4.1 \pm 0.3$ & $4.0 \pm 0.3$ & $0.00^{*}$ \\
HCV-RNA (millionlU/mL) & $3.12 \pm 2.14$ & $3.88 \pm 2.55$ & $0.00^{*}$ \\
\hline
\end{tabular}

Data are presented as mean $\pm S D, P$ value $<0.05$ is significant

\section{Correlation Studies}

Statistical correlations were determined by the non-parametric Spearmant test in order to find any relation of statistical significance between HCV RNA absolute difference and LDL, ALT, AST and, Alb absolute differences. There was an inverse statistically significant correlation $(r=-0.388, p=0.034)$ between the HCV RNA absolute viral load differences and LDL level absolute differences (the lower the LDL differences, the higher the HCV RNA differences). There was an inverse statistically significant correlation ( $r=-0.42$, $\mathrm{p}=0.021$ ) between HCV RNA absolute differences and LDL level percent differences (the higher the LDL percent differences, the lower the HCV RNA absolute differences (Tables 2, 3). 
Table 2: Correlation between HCV viral load level absolute differences and LDL, ALT, AST and Alb absolute levels differences

\begin{tabular}{l|lccc|}
\hline \multirow{2}{*}{ HCV RNA differences } & \multicolumn{2}{|c}{ LDL differences } & \multicolumn{2}{c|}{ HCV RNA differences } \\
\cline { 2 - 5 } & rvalue & p value & rvalue & p value \\
ALT differences & $-0.388^{*}$ & 00.034 & - & - \\
AST differences & -0.059 & 0.755 & 0.144 & 0.447 \\
Alb differences & -0.277 & 0.139 & -0.185 & 0.329 \\
*p value < 0.05 is significant, HCV=Hepatitis C virus, ALT=alanine aminotransferase, AST= aspar- \\
tate transferase. ALB=albumin
\end{tabular}

However, there was no statistically significant correlation of between absolute differences of RNA levels and other biochemical parameters such as AST, ALT and Alb absolute differences(table 3). Using MANOVA test, we studied HCV RNA viral load difference as dependent variable and LDL, ALT, AST and Alb differences as the independent variables. We found that the predictive variables for HCV RNA viral load level differences were LDL level differences and LDL percent differences whereas AST, ALT, and Albumin differences were not. From the previous results, using a regression analysis (Table 4) we can predict the difference in HCV RNA viral load level by using the following equation: $R N A_{1}-R N A_{2}$ (million $I U / \mathrm{mL}$ ) = $1.73+\left[-0.0225 \times\left(L D L_{1}-L D L_{2}\right)(\mathrm{mg} / \mathrm{dL})\right]$ where; $0.0225=$ regression coefficient; $1.73=$ con stant of coefficient (table 4).

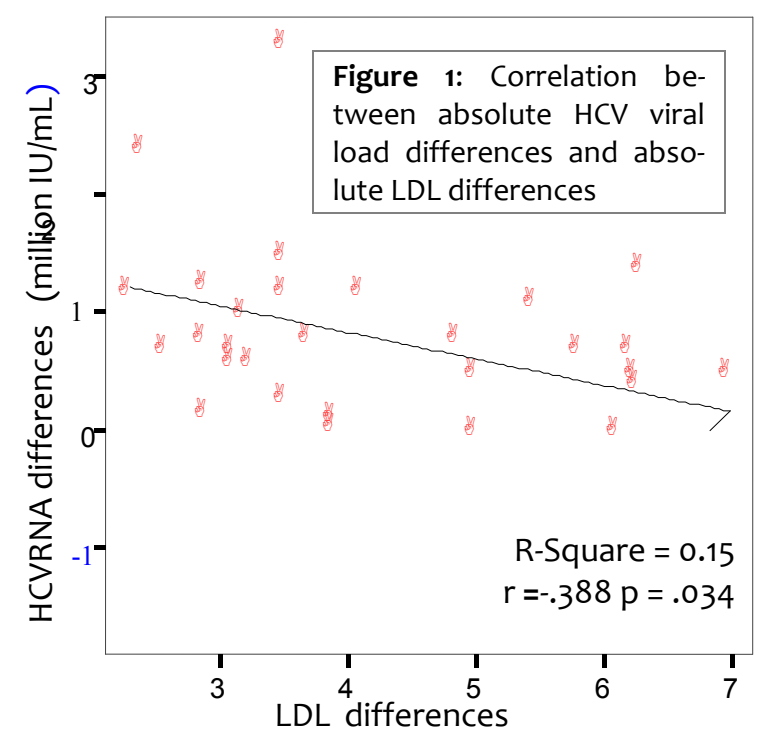

\section{Discussion}

$\mathrm{HCV}$ infection is a major cause of chronic liver disease worldwide. It is a very important health problem in Egypt, with seroprevalence rates of $10-20 \%$ among blood donors, and even higher rates reported among segments of the general population $^{(1)}$. LDL refers to a class and range of lipoprotein particles, commonly referred as "bad cholesterol" due to the link between high LDL levels and cardiovascular diseases leading to myocardial infarctions and strokes ${ }^{(2)}$. LDLR are plasma membrane proteins, which are widely expressed, and are capable of binding with high affinity to circulating LDL particles through their interaction with apolipo-protein B-100 ${ }^{(3,4)}$. Previous studies had identified an association between HCV and LDL in human sera and subsequently an interaction between HCV or HCV-LDL complexes with the cellular LDL receptor. Moreover, a relationship between chronic hepatitis $C$ virus infection and lipid metabolism has been suggested ${ }^{(12,13,18,17)}$. Therefore, free beta-lipoproteins in human serum may regulate the rate of hepatocyte infection by competing with the virus. Thus, serum HCV levels can be regulated by the rise and fall of serum betalipoproteins since the infection rate of virions influences $\mathrm{HCV}$ replication in hepatocytes and release of virions by hepatocytes ${ }^{(19)}$. 
Table 3: Correlation between HCV RNA absolute differences versus LDL \% differences, AST\% differences, ALT\% differences, Alb \% differences

\begin{tabular}{|l|cc|}
\hline & \multicolumn{2}{|c|}{ HCV RNA differences } \\
\cline { 2 - 3 } & rvalue & P value \\
\hline LDL\% difference & $-0.420^{*}$ & 0.021 \\
ALT\% difference & -0.047 & 0.805 \\
AST\% difference & -0.153 & 0.419 \\
ALB\% difference & -0.050 & 0.792 \\
\hline
\end{tabular}

* Correlation is significant at the 0.05 level

Table 4: Regression analysis of HCV RNA and LDL absolute differences

\begin{tabular}{|c|c|c|c|c|c|}
\hline \multirow{2}{*}{ Difference } & \multicolumn{2}{|c|}{$\begin{array}{l}\text { Unstandardized } \\
\text { Coefficients }\end{array}$} & \multirow{2}{*}{$\begin{array}{c}\text { Standardized } \\
\text { Coefficients } \\
\text { Beta } \\
\end{array}$} & \multirow[t]{2}{*}{ T value } & \multirow[t]{2}{*}{$P$ value } \\
\hline & B & Std. Error & & & \\
\hline Constant & 1.73 & 0.46 & & 3.785 & $0.001 *$ \\
\hline LDL & -0.0225 & 0.028 & -0.388 & -2.228 & 0.034 * \\
\hline
\end{tabular}

The present work studied 30 adult patients; 20 to 58 years old. 21 males (70\%) and 9 females (30\%); attended the clinic for follow up of their hyperlipidemia; all patients were chronic hepatitis $C$ patients attended the clinic more than one time with LDL levels difference of no less than $10 \%$ at two successive visit were followed up. Patients receiving anti-viral treatment for $\mathrm{HCV}$, receiving treatment for hyperlipidemia, or suffering from chronic liver disease due to causes other than HCV were excluded from the study. All participants included in the study were subjected to medical history taking, complete clinical examination and base-line laboratory investigations: LDL level, liver function tests (AST, ALT, and Albumin), and HCV RNA viral load. The present study found a statistically significant difference between the first and second results of LDL, AST, ALT, Alb and RNA, by performing a paired $\mathrm{T}$ - test statistics. The present study demonstrated an inverse statistically significant correlation between the absol-ute HCV RNA viral load differences and absolute LDL level differences. (The lower the absolute LDL differences, the higher the absolute HCV RNA viral load differen- ces). This result agrees with the results of Enjoji et al ${ }^{(19)}$ who found that HCV-Ag levels were negatively correlated with the increased beta-lipoproteins. The results support the concept that LDLR is a HCV receptor and that beta-lipoproteins competitively inhibit the infection of hepatocytes with HCV through the LDLR. In addition, Petit et al $^{(20)}$ had found that Levels of apo $B$ were negatively correlated with steatosis and HCV viral load. This last correlation was strong for non-1 genotype and genotype 3 but was not found in genotype 1. In multivariate analysis, low apo B concentration was significantly associated with high HCV viral load. Petit et $\mathrm{al}^{(20)}$ concluded that in chronic HCV patients, hypobetalipoproteinemia occurs already in the early stages of HCV infection before the development of liver cirrhosis and that correlation between apo B levels and HCV viral load seems to confirm the interaction between hepatitis $C$ infection and lipoprotein metabolism. In 1986, Brown \& Goldstein ${ }^{(3)}$ demonstrated that expression of LDL receptors on the cell surface of hepatocytes is inversely related to the concentration of LDL cholesterol. Results presenting a negative correlation 
between LDL-R expression and LDL cholesterol are consistent with this concept. These results are consistent with the result of our study, which found an inverse statistically significant correlation between the absolute HCV RNA viral load differences and absolute LDL level differences. However, in 2007, Petit et al $^{(21)}$ demonstrated that LDLR expression was negatively correlated with total cholesterol, with LDL cholesterol, and with apolipoprotein B (apoB) level. Also, Petit et $\mathrm{al}^{(21)}$ demonstrated that LDLR expression was positively correlated with $\mathrm{HCV}$ viral load but HCV viral load was not correlated with LDL cholesterol. Serfaty et $\mathrm{al}^{(22)}$ concluded that the correction of hypobetalipoproteinemia following $\mathrm{HCV}$ eradication suggests that HCV itself could induce hypobetalipoproteinemia and steatosis. Also, the present study demonstrated an inverse statistically significant correlation between the absolute HCV RNA viral load differences and LDL percent differences (the higher the LDL \% differences, the lower the absolute HCV RNA viral load differences). There was no correlation between absolute HCV RNA viral load level differences and differences in the levels of liver enzymes (AST, ALT) or Alb. Multivariate stepwise regression analysis was used to identify the predictive variables for absolute HCV RNA viral load level differences (Figure 1). Using MANOVA test, we studied HCV RNA viral load difference as dependent variable and LDL, ALT, AST and Alb differences as the independent variables. We found that the predictive variables for HCV RNA viral load level differences were LDL level differences and LDL percent differences whereas AST, ALT, and Albumin differences were not. Gopal et $\mathrm{al}^{(23)}$ found that the good prognostic factor regarding viral treatment response of high LDL cholesterol concentration could be the consequence of low LDL-R expression. HCV-positive patients had predicted LDL levels $19 \mathrm{mg} / \mathrm{dL}$ lower than those of HCV-negative subjects $^{(24)}$. From this data, our study creates an equation that we can use for calculation of the predicted HCV RNA difference level using a regression analysis; by using the difference in LDL levels as follow: $\mathrm{RNA}_{1}-\mathrm{RNA}_{2}=1.73+[-0.0225 \mathrm{x}$ $\left.\left(\mathrm{LDL}_{1}-\mathrm{LDL}_{2}\right)\right]$.

\section{Conclusions}

Our study concluded that low-density lipoprotein levels have an effect on the measurement of hepatitis $C$ viral load in chronic hepatitis $C$ patients. Therefore, this must be taken in consideration when chronic hepatitis $C$ patients with a history of dyslipidemia perform a HCV RNA viral load by PCR for follow up; a fasting sample should be taken from the patient in order to assess LDL level to avoid incorrect results of HCV RNA viral load due to the effect of the difference in LDL levels, otherwise Labs can use the equation proposed in our study in order to predict the difference in HCV RNA viral load in correspondence to change in LDL levels.

\section{References}

1. Darwish MA, Faris R, Clemens JD, Rao MR, Edelman R. (1996): High seroprevalence of hepa-titis A, B, C, and E viruses in residents in an Egyptian village in the Nile Delta: A pilot study. Am J Trop Med Hyg; 54:6554-8.

2. Rifai N (1986): Lipoproteins and apolipoproteins composition, metabolism and association with coronary heart disease. Arch Pathol Lab Med; 110:694.

3. Brown MS, and Goldstein JL. (1986): "A receptor-mediated pathway for cholesterol homeostasis." Science, 232, 34-47.

4. Defesche JC (2004): Low-density lipoprotein receptor- its structure, function, and mutations. Semin Vas Med; 4 (1): 5- 
11.

5. Wang J-T, Sheu J-C, Lin J-T et al (1992) : Detection of replicative form of hepatitis $C$ virus RNA in peripheral blood mononuclear cells. J Infect Dis; 166: 1167-1169

6. Bertolini L, Iovacci S, Ponzetto A et al(1993 ):The human bone marrow B cell line $C E$, susceptible to hepatitis $C$ virus infection. Res Virol; 144: 281-285.

7. Cribier B, Schmitt $C$, Bingen $A$ et al (1995): In vitro infection of periferel blood mononuclear cells by hepatitis $C$ virus. J Gen Virol; 76: 2485-2491

8. Shimizu YK, Feinstone SM, Kohara $M$ et al (1996): Hepatitis C virus: detection of intracellular virus particles by electron microscopy. Hepatology; 23: 205-209

9. Shimizu YK, Purcell RH, Yoshikura $H$. (1993): Correlation between the infectivity of hepatitis $C$ virus in vivo and its infectivity in vitro. Proc Natl Acad Sci USA; 90: 6037-6041.

10. Seipp S, Muller HM, Pfaff E. et al (1997): Establishment of persistent hepatitis C virus infection and replication in vitro. $J$ Gen Virol; 78: 2467- 2476

11. Sugiyama $K$, Kato $N$, Ikeda $M$. et al (1997): Hepatitis C virus in lymph nodes and female reproductive organs. Jpn J Cancer Res; 88: 925-927

12. Hijikata $M$, Shimizu $Y K$, Kato $H$ et al (1993): Equilibrium centrifugation studies of hepatitis $C$ virus: evidence for circulating immune complexes. J Virol; 67: 1953-1958

13. Thomssen R, Bonk S, Thiele A. (1993): Density heterogeneities of hepatitis $C$ virus in human sera due to the binding of beta-lipoproteins and immunoglobulins. Med Microbiol Immunol 182, 329334.

14. Thomssen R, Bonk S, Propfe C. et al (1992): Association of hepatitis $C$ virus in human sera with beta-lipoprotein. Med Microbiol Immunol; 181: 293-300.

15. Agnello V, Abel G, Elfahal M. et al (1999): Hepatitis $C$ virus and other flaviviridae viruses enter cells via low density lipo- protein receptor. Proc Natl Acad Sci USA; 96: 12766-12771

16. Monazahian $\mathrm{M}$, Boehme I, Bonk $\mathrm{S}$ et al(1999): Low density lipoprotein receptor as a candidate receptor for hepatitis C virus. J Med Virol; 57: 223-229

17. Prince $A M$, Huima-Byron T, Parker TS \& Levine DM (1996): Visualization of hepatitis $C$ virions and putative defective interfering particles isolated from lowdensity lipoproteins. J Viral Hepat 3, 1117.

18. Xiang J, Klinzman D, McLinden J. et al (1998): Characterization of hepatitis $G$ virus (GB-C virus) particles: evidence for a nucleocapsid and expression of sequences upstream of the E1 protein. J. Virol; 72:2738-2744.

19. Enjoji $M$, Nakamuta $M$, Kinukawa $N$. et al (2000): Beta-lipoproteins influence the serum level of hepatitis $C$ virus. Medical Science Monitor, 6(5):841-844.

20. Petit JM, Benichou M, Duvillard L. (2003): Hepatitis C virus-associated hypobetalipoproteinemia is correlated with plasma viral load, steatosis, and liver fibrosis. Am J Gastroenterol ; 98(5): 1150-4.

21. Petit JM, Minello A, Duvillard L, et al.. (2007):Cell surface expression of LDL receptor in chronic hepatitis C: correlation with viral load; Am J Physiol Endocrinol Metab 293: E416-E420

22. Serfaty L, Andreani T, Giral P, Carbonell N, Chazouilleres O, Poupon R. (2001): Hepatitis $C$ virus induced hypobetalipoproteinemia: a possible mechanism for steatosis in chronic hepatitis C. J Hepatol;34 (3):428-34.

23. Gopal K, Johnson T C, Gopal S, et al (2006): Correlation between beta-lipoprotein levels and outcome of hepatitis C treatment. Hepatology 44(2): 335-340.

24. Polgreen PM, Fultz SL, Justice AC. (2004): Association of hypocholesterolaemia with hepatitis $C$ virus infection in HIV-infected people. HIV Med.; 5 (3):144-5. 